\title{
Typology of Consonantal Insertions
}

\author{
Marzena Żygis \\ Zentrum für Allgemeine Sprachwissenschaft, Berlin
}

The present study, based on a typological survey of ca. 70 languages, offers a systematization of consonantal insertions by classifying them into three main types: grammatical, phonetic, and prosodic insertions. The three epenthesis types essentially differ from each other in terms of preferred sounds, domains of application, the role of segmental context, their occurrence cross-linguistically, the extent of variation and phonetic explication.

The present investigation is significantly different from other analyses of consonantal epentheses in the sense that it neither invokes markedness nor diachronic state of the processes under discussion. Instead, it considers the different nature of the epenthetic segments by referring to the representational levels and/or domains which are relevant for their appearance.

\section{Introduction}

The dynamics of language manifests itself inter alia in the lack of mapping between underlying and surface representations. Underlying segments are sometimes not realized, and vice versa, sounds which are not present underlyingly are articulated and perceived as such. Phonologically, in the former case we are faced with deletion processes, and in the latter with insertions. Different reasons are responsible for both types of processes, including prosodic constraints, stress conditions, segmental neighbourhood, phonotactic requirements, and others.

The present paper focuses on consonantal insertions, i.e. processes in which consonants which are not present underlyingly appear on the phonetic surface. The inserted segments have a different status depending on the language: they can be phonemes, allophones or even sounds which do not occur in a given language. The only criterion adopted for the purposes of the present analysis is that they are perceived as segments. Thus, for example, inserted articulatory gestures or acoustic traces which are not perceived by listeners as segments will not be treated as insertions.

Examples of consonantal insertions are provided in (2). 
(2)

Insertions

$\begin{array}{llll}\text { wesen+lich } & \text { wesen[t]lich } & \text { 'considerably' } & \text { German } \\ \text { sytuacja } & \text { sytu[w]acja } & \text { 'situation' } & \text { Polish } \\ \text { aapa inni } & {[?] \text { aapa inni }} & \text { 'What is this? } & \text { Selayarese }\end{array}$

Although, at first sight, the examples in (2) illustrate the same kind of process, i.e. epenthesis, each process is in fact different in its nature and motivation as will be analyzed in detail below. The present study proposes a classification of all epentheses into three main categories, i.e. (i) grammatical, (ii) phonetic, and (iii) prosodic. In the remaining part of the article, all insertion types will be discussed in detail and illustrated with examples.

The article is organized as follows. In section 2 a classification of various types of insertion processes based on a typological study is proposed. Section 3 discusses selected accounts of consonantal insertion processes. Section 4 concludes.

\section{Typology of insertions}

For the purposes of the present study, ca. 70 typologically different languages have been investigated (Austronesian, Romance, Slavic, Germanic, and Semitic among others). The survey leads to a classification of the insertions into three main types:

(3) Insertion types

i) grammatical

ii) phonetic

iii) prosodic

Grammatical insertions comprise all types of insertions which are conditioned morphologically, syntactically and morpho-syntactically, among others. By contrast, phonetic insertions are found on the surface representations and are explicable on articulatory, acoustic, aerodynamic or perceptual bases. Finally, prosodically conditioned insertions include epenthetical processes which refer to prosodic boundaries/domains.

Besides the main insertion types listed in (3), there are also cases attested the classification of which is not straightforward. This is a natural consequence of the interaction of different components, as e.g. syntax and prosody. Such insertions will also be considered in subsequent sections.

In the following, all insertion types will be discussed in detail and illustrated with examples. The discussion comprises the preferred sounds of a 
given type, their insertion domains, and the role of segmental context as well as phonetics in the explanation of the processes. In addition, it will be analyzed to what extent the processes are subject to inter-speaker variation.

\subsection{Grammatical insertions}

Several insertions already take place in the grammar of a given language. They are idiosyncratic, characteristic of a particular language. Insertions of this type are subject to phonological, morphological or syntactic regularities and are determined strictly by grammatical categories or constituents. Preferably, in this type of insertions coronal sounds are dominating, albeit labial, velar or glottal sounds are found as well. In a selected number of cases the processes depend on segmental context as well, as will be illustrated below. Finally, the insertions are not subject to inter- or intra-speaker variation and are rather resistant to other factors, such as e.g. speech rate.

For reasons of simplification, the following discussion is limited to morphologically and syntactically conditioned epentheses. It is assumed that morphological insertions take place within words, i.e. mainly between prefixes and stems or stems and suffixes and between constituents of compounds, while syntactic insertions occur between words, i.e. at a syntactic level.

A classic, often cited example is [t]-insertion in Axinica Campa which is morphologically restricted: it takes place only in suffixation processes. Consider the examples in (4).

Axinica Campa

/i-N-koma-i/ [inkomati]

'he will paddle'

/i-N-koma-aa-i/ [inkomataati]

'he will paddle again'

(Payne 1981:108, Lombardi 2002:239)

Lombardi (2002), when discussing the examples in (4), draws attention to the fact that another potential candidate for insertion, i.e. the glottal stop [?] is not possible here since Axinica Campa does not allow [?] at all, cf. discussion in 3.2.

[t]-insertion is also found e.g. in Odawa, where it takes place at a personal prefix and stem boundary. If, however, the same prefix is attached to different classes of nouns (of inalienable possession), the hiatus is resolved by deletion of a vowel. Consider examples in (5a) and (b).

Odawa

a) $/$ ki-akat-i/ [kitakat $\overline{f i}] \quad$ 'you are shy' 

/ni-ompass/
[nito:mpass]
'you (pl) oversleep'
b) /ni-o:ss/
[no:ss]
'my bus'
(Pigott 1980)

Frequent epenthetical processes include glide insertions which on the one hand take place in a well-defined morphological context and on the other hand might be governed phonologically, see discussion below. For example, in Sinhala the underlying vowel hiatus at root-suffix boundaries is always resolved, whereby the type of repaired strategy depends on the lexical category of the root. For instance, the hiatus in nouns is always resolved by glide insertion. Examples in (6) illustrate this point. (Verbs prefer to resolve hiatus through deletion of an input vowel or, in case of both monosyllabic morphemes, glide epenthesis applies as a last-resort strategy).

(6)

$\begin{array}{lll}\text { Sinhala } & & \\ / \mathrm{ræ}+\mathrm{a} / & {[\text { ræjə] }} & \text { 'night, sg.def.' } \\ / \text { toppi+a/ } & \text { [toppijə] } & \text { 'hat, sg.def.' } \\ \text { /ašu+a/ } & \text { [ašuwə] } & \text { 'attic, sg.def.' } \\ \text { /maaligaa }+\mathrm{a} / & \text { [maaligaawə] } & \text { 'palace, sg.def.' }\end{array}$

(Smith 2001:63)

Similarly, in Shona [j] is inserted in verb inflections when the second vowel in the sequence is a coronal vowel [e] or [i]. It is also epenthesized in roots when the second vowel is [a] and the first vowel is either [e] or [i], or when the second vowel is a coronal vowel. This is exemplified in (7).

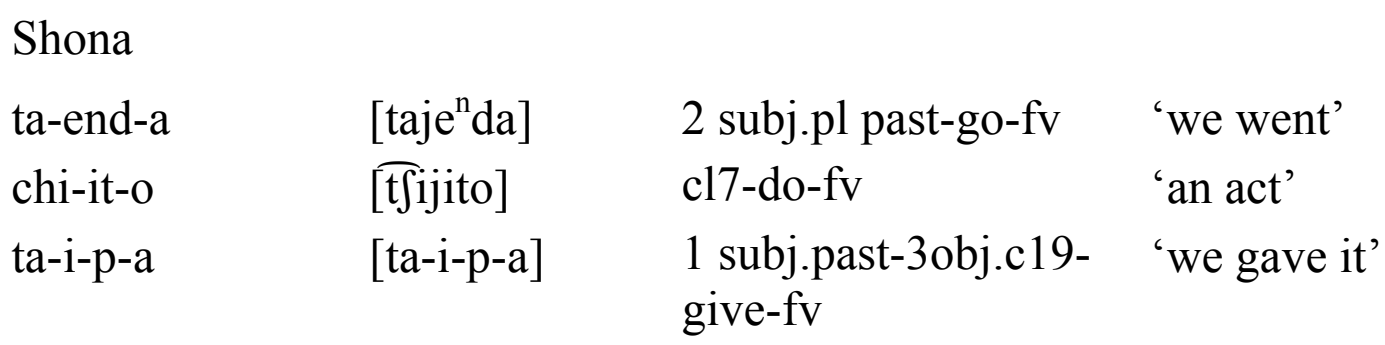

(Mudzingwa 2007:10)

In Shona [w]-insertion also takes place: the glide is inserted in roots and verb inflections when the second vowel in the sequence is a labial vowel $[\mathrm{o}]$ or $[\mathrm{u}]$; it is also epenthesized in roots when the second vowel is [a] and the first vowel is a labial vowel. This is shown in (8). 
(8)

Shona

$\begin{array}{llll}\text { a-or-a } & \mathrm{a}[\mathrm{w}] \text { ora } & \text { 3subj.cl6pat-rot-fv } & \text { 'they rot' } \\ \text { duo } & \mathrm{du}[\mathrm{w}] \mathrm{o} & \text { cl5.fish trap } & \text { 'fish trap' } \\ \text { ama-úta } & \mathrm{ama}[\mathrm{w}] \text { úta } & \text { clla-deaf person } & \text { 'deaf person' }\end{array}$

(Mudzingwa 2007:10)

[w]- and [j]-insertions are found in several other languages (see also examples discussed in section 2.2.1). Phonologically, the insertions in most cases serve to resolve hiatus by inserting a consonantal onset. Hiatus resolution is frequently analyzed as either the so-called default insertion or as feature(s) spreading. In the former case, the whole segment is inserted and it does not share features with neighbouring sounds. Such cases are also not explicable phonetically. In the latter case, a feature or even a bundle of features spreads from the existing vowel, creating a new segment. An example of [w]-insertion is presented in (9), cf. Mudzingwa (2007).

(9) Spreading of features in [w]-insertion

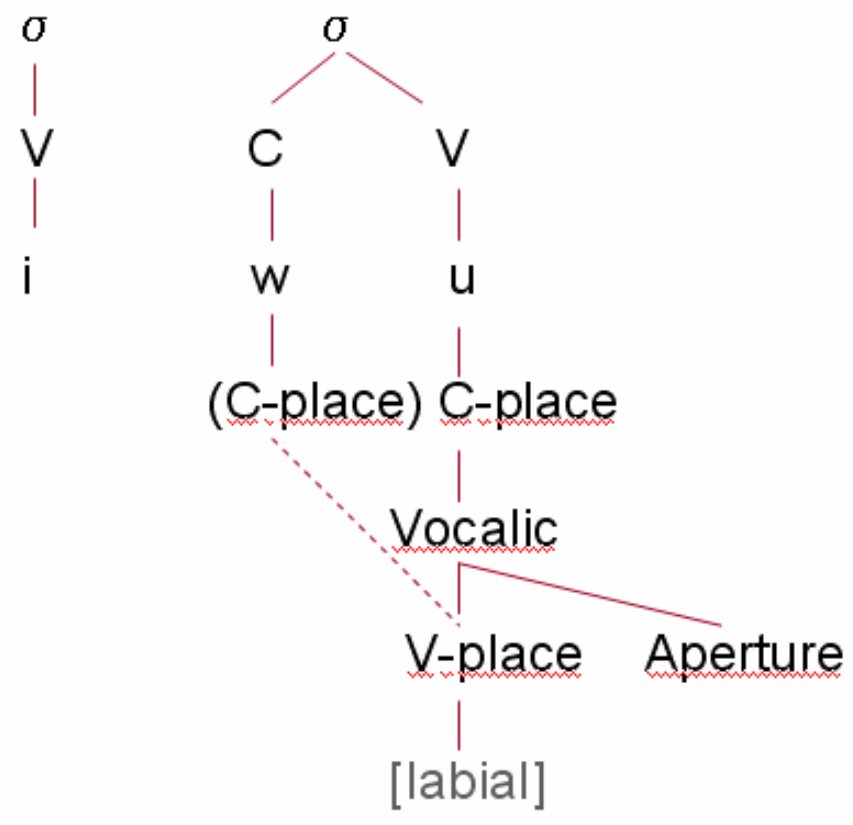

The representation in (9) shows that the inserted sound is not accidental but rather depends on the feature content of the neighbouring sound. It receives vocalic-place features including [labial] via spreading from the following [u]. This conclusion also links phonology with phonetics, where the emergence of glides is due to a percept of formant transition between the adjacent vowels. This is discussed in detail in section 2.2.1. 
Grammatical insertions also comprise the so-called linking elements (or linking morphemes) which are found mainly in compounds. Wiese (2000) lists several of such morphemes for Standard German $(<-\mathrm{t},-\mathrm{s},-\mathrm{es},-\mathrm{er},-\mathrm{e},-\mathrm{es},-\mathrm{en},-\mathrm{n}>$ ) the appearance of which is generally not predictable. Wiese argues that $[\mathrm{t}]$ and [s] are in fact not morphemes (e.g. plural markers) but inserted consonants: [s]insertion applies in the case of certain nouns in the non-head position of compounds, cf. (10a), whereas [t]-insertion is found in morphological formations in which the first compound part ends in [n], cf. (10b). Obviously, such insertions are not explicable in phonological terms as was the case for the Shona examples presented above.

(10) Standard German

a) Schwingung $+s+z a h l$ 'frequency' Lösung $+\mathbf{s}+$ vorschlag 'proposal for solution'

$\begin{array}{ll}\text { b) } & \text { 'orden }+\mathrm{t}+\text { lich } \\ \text { mein }+ \text { et }+ \text { wegen } & \text { 'I don't mind' }\end{array}$

Wiese $(2000: 145,146)$

In several other Germanic languages compounds are linked with inserted sounds. For example, in Dutch the nominal compounds may be linked together with [s] or [ə]/[ən] written $<\mathrm{s}>$, and $<\mathrm{en}>$ or $<\mathrm{e}>$ respectively. The linking segments are originally genitive markers (de Schutter 1994:453); examples are provided in (11).

(11) Dutch

$\begin{array}{ll}\text { arbeider }+ \text { s }+ \text { dochter } & \text { 'workman's daughter' } \\ \text { binn }+ \text { en }+ \text { pretje } & \text { 'private joke' } \\ \text { alleman }+ \text { s }+ \text { vriend } & \text { 'everybody's friend' }\end{array}$

(de Schutter 1994:453)

Similarly, in Swedish the linking segment $/ \mathrm{s} /$ and a vowel are sometimes attached to the first element, as shown in (12).

(12) Swedish

$\begin{array}{ll}\text { land }+ \text { s+ting } & \text { 'county council' } \\ \text { läs }+ \text { e+bok } & \text { 'textbook' } \\ \text { dag }+ \text { s }+ \text { inkomst } & \text { 'daily income' } \\ \text { kvinn-o-arbete } & \text { 'women's work' }\end{array}$

(Andersson 1994:277) 
In Icelandic the so-called genitive compound appears with [s] (Thráinsson 1994:165). The linking element [s] is often required when the first part of a compound is itself a compound, e.g. borðplata 'table top'(stem compound) vs. skrifborð[s]plata 'writing desk top' (genitive compound). As noted by Thráinsson (1994) it is difficult to formulate the rules which underlie the formation of compounds and the appearance of [s] in particular.

In several of the cases presented above it is [s] which connects the compound parts. Although the insertions are not motivated phonetically, i.e. they can not be predicted on the base of the phonetic characteristics of the neighbouring sounds, it is still worth considering that [s] is an extremely salient sound from a perceptual point of view due to its high-frequency noisy characteristics.

There are also other coronals which are inserted, namely rhotics and nasals. The so-called intrusive [r] is found in Bavarian (cf. Bayer \& Brander 2008, Bayer \& Brander submitted, Ortmann 1998) or in Middle Frankish spoken in Nürnberg in Northern Bavaria (Kabak, \& Schiering 2006) where it appears intervocalically, cf. (13).

(13) Middle Frankish

a) [tsu(-r-)əne $\left.\int u \cdot 1\right]$

'to a school'

$\mathrm{zu}[\mathrm{r}]$ einer Schule

b) [vov(-r-)r bin]

'where I am'

wo $[\mathrm{r}]$ ich bin

(Kabak \& Schiering 2006:69)

The [r]-insertions in Middle Frankish apply in sequences of two function words, i.e. in preposition-determiner, complementizer-pronoun and complementizerdeterminer combinations. It should be also noted that the [r]-intrusion is not found within words or compounds. Kabak \& Schiering (2006) argue that the function words create a foot which is attached to a phonological word, a fact which is crucial for their analysis. This example shows the interaction of syntactic and prosodic constituents.

In Northern Bavarian or in East Frankonian consonantal insertions may appear with lexical verbs as shown in (14). Note that in the former case an [r] and in the latter case an $[\mathrm{n}]$ is epenthesized.

(14) Northern Bavarian
a) $\quad$ zi:a-r-i $]$
'I see'
sehe ich

b) East Frankonian 
[gi-n-i] 'I go'

gehe ich

(Kabak \& Schiering 2006:71)

Kabak \& Schiering (2006) notice that the common denominator of lexical words in (14) and complementizers in structures as in (13b) is that they occupy the same syntactic position, i.e. the COMP $\left(\mathrm{C}^{0}\right)$ slot. A similar conclusion is also drawn by Ortmann (1998) with respect to High Alemannic, where [n] is epenthesized, cf. the examples in (15).

(15) High Alemannic

a) so, wie-n-er gsait hätt

'right as he said'

so as-EP-he said has

b) däs Stuck, wo-n-ere id gfalle hätt

'the play she didn't like' the play REL-EP-her not pleased has

Ortmann (1998:59)

Another well-known example of grammatical insertions is [x]-insertion at certain morphological and syntactic structures found in non-rhotic dialects spoken in several parts of England, Wales and Australia as well as in several non-rhotic dialects of the United States. This phenomenon has been a subject of extensive theoretical and empirical studies (cf. e.g. McCarthy 1991, 1993, Gutch 1992, Gick 1999, Foulkes \& Docherty 2000, McMahon 2000, Ito \& Mester 2009).

The [x]-insertion appears after the non-high vowels [ə, o:, a:], cf. (16a), as pointed out by Wells (1982). This fully productive process is found in acronyms, loan words and even in the pronunciation of foreign languages, cf. the third example from German in (16b). (Intrusive [ $\mathrm{x}]$ arose historically as hypocorrection of linking $[\mathrm{I}]$ in non-rhotic dialects.)

(16) English I-insertion

a) the idea-[x]-is

law-[x]-and order

b) as far as NAFTA-I-is concerned

schwa-[x]-insertion

Ich bin ja-[x]-auch fertig

'I'm also done'

Ito \& Mester (2009:167) 
The intrusive [x] is also found word-internally, as for instance in draw[I]ing or withdraw[I] al.

As pointed out by Kahn (1976) and McCarthy (1993), this fully productive process is restricted insofar as the intrusive [I] does not appear after function words, e.g. 'the apples' is pronounced as [ði æplz] and not *[ði . æ æplz].

The appearance of intrusive $[\mathrm{r}]$ is also prosodically conditioned. It has been argued that the insertion of $[\mathrm{r}]$ is a manifestation of the requirement for maximal prosodic words to have an onset (cf. e.g. Ito \& Mester to appear, cf. also McCarthy 1993).

Even if the process is determined by the word type and prosodic requirements, it has been argued that it is at least partly motivated phonetically, cf. McMahon, Foulkes \& Tollfree (1994), Gick (1999), Gick, Kang \& Whalen (2002), and Gick (2002). McMahon et al. (1994) propose that if the anterior raising gesture of $[\mathrm{I}]$ were removed, the remaining tongue configuration would resemble the articulation of schwa. This hypothesis is further investigated by Gick (1999) who argues that all final schwas in lexical words (in dialects with intrusive $[\mathrm{I}]$ ) are allophones of $/ \mathrm{I} /$. Both studies also support the prediction that an [I]-like pharyngeal constriction should be found in schwa. Furthermore, the analysis of midsagittal MRIs of the vocal tracts of several vowels as well as [I] and [1] by Gick, Kang \& Whalen (2002) reveals that at least in some dialects of American English, a single postoral gesture is shared between [1] and [0] and between [I] and schwa. Finally, in Gick's study (2002) on schwas, one subject even showed a bimodal pattern in schwa, which may indicate that this subject has distinct schwas in lexical vs. functional words, a property that has also been observed with respect to $[\mathrm{I}]$ in $\mathrm{I}$-vocalizing dialects. In summary, this example illustrates an interaction of grammar, prosody and phonetics.

Another example of a grammatical insertion is [g]-insertion taking place in Mongolian. If the base ends in a long vowel or a diphthong, [g] is inserted before suffixes with a long initial vowel. Consider examples in (17).

\section{(17) Mongolian}

$\begin{array}{lll}\text { a) ablative /-AAs/ } & \text { dalai 'sea' } & \text { dalai[g]aas } \\ & \text { dülii 'deaf' } & \text { dülii[g]ees }\end{array}$

b) genitive /-IIn/ xii 'air' xii[g]iin

debee 'swampland' debee[g]iin

Rialland \& Djamouri (1984)

In summary, grammatical insertions as illustrated by several examples are dominated by coronal sounds (stops, glides, rhotics). They are idiosyncratic, 
hence their presence is not predictable, albeit at least in selected cases phonetic motivation cannot be excluded. These insertions are not subject to variation.

\subsection{Phonetic insertions}

Phonetic insertions considerably differ from grammatical ones as the former emerge on the surface representation as a natural consequence of the interaction of phonetic factors. Therefore, in contrast to grammatical insertions, they are explicable solely in phonetic terms. This type of insertion comprises a wide spectrum of possible sounds the occurrence of which depends exclusively on the context, i.e. neighbouring sounds. As shown below, the most frequent insertions are stops produced at different places of articulation as well as glides found in various vocalic contexts. Since the insertions are phonetically grounded, they are expected to occur in typologically different languages, a hypothesis confirmed by the examples provided below. Phonetic insertions are subject to variation, a point which is discussed below.

Phonetic insertions are often gradual processes evolving e.g. from overlapping gestures which at the beginning may not be perceived as categorical sound. Therefore, it is not obvious to predict the final (by)product of a given process and, moreover, to classify it as an insertion. For the purposes of the present study, only phonetic instances in terms of articulatory gestures, acoustic traces, etc. which are perceived as categorical sounds are treated as phonetic insertions. As several studies show, the phonetic insertion can also be incorporated into underlying representation and orthography being a final product of an insertion process. Before the insertion enters the orthographic convention of a given language, it sporadically happens to appear in orthographical representation and is generally treated as a mistake. For example, the Polish word $<$ sytuacja $>$ is permanently written by children as <sytułacja $>$, with $<\nmid>$ corresponding to [w] in IPA terms.

In the following, the most frequent phonetic insertions along with their phonetic explanations will be provided.

Among the most common outputs of phonetic insertions are the glides [w] and [j]. The examples in (18a) and (18b) illustrate glide insertions in Japanese and Polish.

[w] and [j]-insertions

a) Japanese

$\begin{array}{lll}\text { guai } & \text { gu[w]ai } & \text { 'condition' } \\ \text { siawase } & \text { si[j]awase } & \text { 'happiness' }\end{array}$

Kawahara (2002)

b) Polish 


$\begin{array}{lll}\text { sytuacja } & \text { sytu[w]acja } & \text { 'situation' } \\ \text { trio } & \text { tri[j]o } & \text { 'trio' }\end{array}$

Rubach (1984)

The context of [w] insertions in (18) always implies the presence of a following or preceding / $\mathrm{u} /$, whereas the glide [j] is inserted in the context of the preceding /i/. Thus, the outputs are not accidental but depend on the neighbouring sounds as has already been mentioned in section 2.1. In contrast to grammatical insertions of this type, the glide insertion is not determined by morphological or syntactic constituents/rules.

Phonetically, it is probably the (lengthened) formant transition of neighbouring sounds which gives the perceptual impression of a new emerging sound (in line with Ohala's 1981 interpretations of sound change). Although such observations have been made intuitively (Blevins 2007), the processes have not been investigated in detail. It is not clear what exact requirements should be met for a formant transition to be perceived as a glide.

In order to gain more insight into the topic, Zygis (2009) conducted a perceptual study which involved the manipulation of transition length in the item [ia]. The transition between [i] and [a] was lengthened from 50 to $230 \mathrm{~ms}$ in $30 \mathrm{~ms}$ steps so that a 7-step continuum was created. Both the total duration of the item as well as the duration of [a] was constant. The files were played twice from a laptop via headphones to ten native speakers of German, three native speakers of Polish and three of English (in all languages, / $\mathrm{j} /$ is present in the phonemic inventory). The informants were asked to write down what they hear. In all answers [j] was heard, albeit at various transition lengths, cf. Table 1. The preliminary results imply that there is no categorical boundary common for the listeners since (i) different results were obtained for the same stimulus independent of the native language of the informant and (ii) variation was found within informant groups with the same native language background, cf. results obtained for five German native speakers presented in Table 2.

Table 1: Responses of a Catalan, German and Polish speaker to different stimuli files.

\begin{tabular}{|l|l|l|l|}
\hline Stimulus & English & German & Polish \\
\hline S_1 50 ms & ja & ija & ija \\
\hline S_2 $80 \mathrm{~ms}$ & ja & ija & ija \\
\hline S_3 110 ms & ija & ija & ija \\
\hline S_4 140 ms & ija & ija & ija \\
\hline S_5 170 ms & ija & ija & ija \\
\hline S_6 200 ms & ija & ijar & ija \\
\hline S_7 230 ms & ija & i:ja & ja \\
\hline
\end{tabular}


Table 2: Responses of five German speakers to different stimuli files.

\begin{tabular}{|l|l|l|l|l|l|}
\hline Stimulus & German 1 & German 2 & German 3 & German 4 & German 5 \\
\hline S_1 50 ms & ija & ija & ija & ija & i:a \\
\hline S_2 80 ms & ija & ija & ija & ija & i:a \\
\hline S_3 110 ms & ija & ija & (i)ja & ija & i:a \\
\hline S_4 140 ms & ija & ija & ja & ija & i:a \\
\hline S_5 170 ms & ija & ja & ja & ija & i:a \\
\hline S_6 200 ms & ija & ja & ia & ija & i:a \\
\hline S_7 230 ms & ja & ja & ea & ja & ja \\
\hline
\end{tabular}

Thus, the preliminary results strongly suggest that the obtained differences might be explicable not only in terms of the language-specific phonological background, but depend on the individual perceptual (and probably production) characteristics as well.

Other frequent insertions comprise stops articulated at different places of articulation. Well-known examples refer to coronal stop [t], the so-called intrusive stop which appears in sonorant-fricative clusters, as shown in (19).

(19) American English

$\begin{array}{ll}\text { [tents] [tensiti] } & \text { 'tense, tensity' } \\ \text { [tendz] [ten] } & \text { 'tens, ten' } \\ \text { [falts] [falsiti] } & \text { 'false, falsity' }\end{array}$

(Fourakis \& Port 1986:1999)

Different phonological and phonetic explanations of the processes in (19) have been proposed; cf. e.g. Zwicky (1972), Donegan \& Stampe (1979) Dinnsen (1980), Wetzels (1985), Clements (1987).

Zwicky (1972) and Dinnsen (1980) argue for a phonological rule describing the epenthesis $\varnothing \rightarrow[\mathrm{t}] / \mathrm{S} \_\mathrm{F}$ ( $\mathrm{S}=$ sonorant, $\mathrm{F}=$ fricative). Ohala (1974) and Donegan \& Stampe (1979) state that the emergence of [t] and [d] in processes shown in (19) does not follow from the rule application but from mistiming effects. Clements (1987) accounts for the process in terms of feature spreading. Ohala (1974) claims that closing the velum before the release of the nasal closure produces a configuration of articulators similar to that of a homorganic stop.

Fourakis \& Port (1986) examined the production of sonorant-fricative and sonorant-stop-fricative clusters by two groups of speakers: South African dialect speakers and American mid-western dialect speakers. Results of an acoustic analysis show a clear difference between the informants: while the South African speakers maintained a contrast in the sequences sonorant-fricative and 
sonorant-stop-fricative, American speakers neutralized the contrast in the sense that they always inserted stops after the sonorant if the fricative was voiceless. If the fricative was voiced, the speakers either omitted the stops in clusters like $/ \mathrm{ldz} /$ or $/ \mathrm{ndz} /$ or sometimes inserted a stop in clusters such as $/ \mathrm{nz} /$ and $/ \mathrm{lz} /$. Fourakis \& Port (1986) also show that the inserted stop in American was significantly shorter than a corresponding underlying stop, and that it also affected the length of the preceding nasal. On the basis of their results, Fourakis \& Port (1986) argue that neither of the explanations proposed in the literature (see Zwicky 1972 and Dinnsen 1980 vs. Ohala 1974 and Donegan \& Stampe 1979 ) is tenable. The insertion rule does not consider the fact that the inserted sounds are different from the underlying. The phonetic explanation as proposed by Ohala (1974) is insofar problematic - according to Fourakis \& Port - as it is supposed to be universally applicable, but as the South African data show it does not appear universally. Instead, the authors propose the application of languagespecific rules, the so-called phase rules which are probably confined within one or two syllabic cycles and are partially controlled by phonological, contextual features. The rules are learned so that they may vary in the details of the articulatory output from speaker to speaker. Finally, the rules may change very rapidly as they are sensitive to pragmatic communicative needs, word frequency, usage frequency, etc.

Although the proposal made by Fourakis \& Port gained much attention in the literature, it is still undeniable that a phonetic explanation given by Ohala (1974) can be still maintained as Ohala does not state that the mistiming of articulators takes place universally; otherwise the epenthesis would take place in every language. The mistiming probably appears due to the inability to finally control the articulators in every statement pronounced by every speaker. It may occur that some realizations are less accurate articulatorily, leading to an articulatory configuration which is perceived in a different way than the planned underlying representation. In fact, such 'misperceptions' trigger a sound change.

It is also worth noting that coronal stop insertions which are similar to the ones presented above are found cross-linguistically. Examples in (20) illustrate [d]-insertion in Spanish.

(20)

Spanish
ven(i)ra $>$ ven[d]rá
$\operatorname{sal(i)ra~}>\operatorname{sal}[d] r a ́$$\quad$ 'he will come'

(Wetzels 1985:287)

In (20) the coronal stop [d] is inserted in two contexts: a) between the nasal $/ \mathrm{n} /$ and the rhotic $/ \mathrm{r} /$, and $\mathrm{b}$ ) between the liquid $/ 1 /$ and the rhotic $/ \mathrm{r} /$. The same insertion contexts are found in Old French. Consider the examples in (21) where 
besides $/ \mathrm{n} / / \mathrm{r} /$ and $/ 1 / / \mathrm{r} /$, the context $/ \mathrm{s} / \_/ \mathrm{r} /$ also triggers the emergence of not only [d] but also [t]. All examples imply deletions of vowels.

(21) Old French

$\begin{array}{ll}\text { menour }>\operatorname{man}[\mathrm{d}] \mathrm{re} & \text { 'smaller' } \\ \text { failir }>\text { fal }[\mathrm{d}] \mathrm{ra} & \text { 'fail, lack' } \\ \text { valier }>\operatorname{val}[\mathrm{d}] \mathrm{ra} & \text { 'be worth' } \\ \text { cousons }>\cos [\mathrm{d}] \mathrm{re} & \text { 'sew' }\end{array}$

(Pigott \& Singh 1985:419)

Vincent (1988) reports that in Italian dialects, [t] can be heard in words in which it is not present underlyingly. His examples refer to contexts such as $/ 1 /[/ s /$ and $/ \mathrm{n} / / \mathrm{s} /$. The appearing [t] optionally undergoes merging with the following $/ \mathrm{s} /$, which eventually leads to the emergence of an affricate. Thus, e.g. falso 'false' or senso 'sense' can be pronounced either with an affricate as [faltso] and [sentso], or with a fricative preceded by a 'less perceptible' plosive, i.e. [fal'so] or [sen ${ }^{\text {so] }}$ (Vincent 1988:291). For a restrictive number of southern Italian speakers the process has spread to labials, i.e. the affected words could be optionally pronounced as affricates or stop+fricative sequences, e.g. tonfo 'thud' is pronounced as [tom ${ }^{\mathrm{p}}$ fo] or [tompfo] and inverno 'winter' as [im $\left.{ }^{\mathrm{b}} \mathrm{verno}\right]$ or [imbverno] Vincent (1988:291).

Next to coronal stops, several insertions found cross-linguistically include labial stops. Examples in (22) show labial insertions from Old and Modern English. (Phonetic explanations of these processes are given below).

$\begin{array}{lll}\text { Old English } & >\text { Middle English } & \\ \text { sceamol } & >\text { scham[b]el } & \text { 'stool' } \\ \text { nemnan } & >\text { nem[p]ne } & \text { 'to name' } \\ \text { æmtig } & >\text { em[p]ti } & \text { 'empty' }\end{array}$

(Pigott \& Singh 1985:418)

Similar processes are found in Modern English and German, where [p] can emerge between a labial nasal [m] and a coronal sound. Examples in (23) illustrate this variable process.

(23) Modern English

warmth

warm[p]th

Thomson

Thom[p]son

(Wetzels 1985:288) 
Standard German

Wams

Wam[p]s 'doublet'

Ramsch

$\operatorname{Ram}[\mathrm{p}] \mathrm{sch} \quad$ 'junk'

Wiese (2000:233)

The emergence of bilabial stops in sequences [mbn] was also found in Old Spanish, as illustrated by the examples in (24).

(24) Old Spanish

$\begin{array}{ll}\text { hominem }>\text { hom }[\mathrm{b}] \mathrm{re} & \text { 'man' } \\ \text { nomine }>\text { nom }[\mathrm{b}] \mathrm{re} & \text { 'woman' }\end{array}$

(Millardet 1923:293ff)

In Ancient Greek, the labial [b] appeared in a well-defined context, namely between the nasal $/ \mathrm{m} /$ and the following sonorant $/ \mathrm{r}, 1 /$. This is shown in (25).
Ancient Greek
gam-ros $>$ gam $[b]$ ros
'married'
a-mrotos $>$ am[b]rotos
'immortal'
me-mlōka $>$ mem[b]lōka
'he walked'
(Wetzels 1985:287)

Ohala (1995:161) also lists several examples from Latin, Landais dialects of French, Old Swedish, and Old Provençal in which the labial stops are inserted between $/ \mathrm{m}_{-} \mathrm{n} /$. The epenthesis emerges in a phonetically natural way, as claimed by Ohala. He shows that it is a temporal overlap of the $/ \mathrm{m} /$ and $/ \mathrm{n} /$ closures which is responsible for [p]- and [b]-epenthesis. The simultaneous labial closure of $/ \mathrm{m} /$ and apical closure of $/ \mathrm{n} /$ create a pocket of air between them. At the time when the labial closure is released, the compressed air undergoes a momentary rarefaction of pressure and is released with a click-like burst. Listeners, as argued by Ohala, are likely to interpret the stop burst auditorily as [p], which creates the basis for their own pronunciation. It is also probable that listeners will interpret the emerging sound as a voiced [b].

Phonologically, examples presented in (19), (21), (24), (25) can be explained by applying the syllable contact law according to which 'a syllable contact $\mathrm{A} \$ \mathrm{~B}$ is the more preferred, the less the Consonantal Strength of the offset A and the greater the Consonantal Strength of the onset B' (Vennemann 1988). In other words, contacts like e.g. [n.d], [1.d], [m.p], [m.b] are favoured over [n.r], [1.r], [m.n], [m.r] since the differences in Consonantal Strength (sonority) are higher in the former than in the latter sequences. 
In summary, a crucial difference between grammatical insertions and phonetic insertions is that the former are determined by a specific morphological/ syntactic context, whereas the latter are the result of articulatory timing relationships of neighbouring sounds which motivates their potential appearance cross-linguistically.

\subsection{Prosodic insertions}

Another type of insertions is primarily prosodically conditioned, i.e. their appearance is determined by prosodic constituents such as syllable, prosodic foot, prosodic word, phonological phrase, intonational phrase, and phonological utterance, cf. prosodic hierarchies postulated by Selkirk (1980 a, b), Booij (1983), Nespor \& Vogel (1988). The insertions are found either at the boundaries of the prosodic constituents or they require a given prosodic constituent as a domain of their application. Since prosodic constituents are often domains of stress assignment, prosodic insertions can also interact with stress.

The most frequent prosodic insertions are glottal stops and glottalizations followed by coronal sounds (see below). They often serve as boundary markers/signals and are subject to inter- and intra-speaker variation. Their occurrence depends among other factors on speech rate, speaker's gender, dialect, register, phrasal position, stress conditions, and others.

It seems that the variation found in prosodic insertions is greater at higher than at lower prosodic boundaries. This could be caused by the fact that lower prosodic constituents are created in the lexicon, cf. e.g. the discussion in Zec (2005); they do not incur phrasal stress or intonation and therefore behave differently from higher ones. This point undoubtedly requires further investigation.

Glottal stops and glottalization of prosodic insertions are perceptually distinct, albeit only to some extent; they are 'merely' boundary markers facilitating prosodic parsing and do not contribute to the content of a given word/phrase. Therefore, sounds such as for example sibilants which are perceptually extremely salient are not inserted as boundary markers. In addition, sounds which are phonemes in a given language are less optimal candidates for appearing at prosodic boundaries as they could potentially lead to confusion and misinterpretation of existing words.

An important question concerning prosodic insertions is whether their appearance is also related to neighbouring sounds, e.g. sounds appearing in the initial position of a prosodic phrase. Several studies have shown that glottal stops/glottalization are found if the prosodic constituent starts with a vowel (cf. examples discussed below). From a phonological point of view such insertions serve to create the constituent onset, mostly the syllable onset needed for the creation of an optimal CV syllable. The fact that vowels and glottal stops do not 
have supraglottal constrictions and share glottal constrictions (see below) favours their co-occurrence. Although it is still not entirely clear whether certain vowels facilitate the appearance of prosodic insertions more than others, a few studies have suggested that glottal stops and glottalization are favoured in the context of following low vowels, which is probably due to their similar larynx configuration (cf. studies discussed below).

The most striking characteristics of glottal stops and glottalization when they are inserted seem to be their huge variability found not only among speakers of a given language but also in the pronunciations of individual speakers. This inter- and intra-speaker variability has been observed in several languages and is argued to be dependent on several parameters such as phrasal position, stressed vs. unstressed syllable, speech rate, segmental context, dialect, speaker's gender, and others (see e.g. American English: Umeda 1978, Pierrehumbert 1994, Pierrehumbert \& Talkin 1991, Redi \& Shattuck-Hufnagel 2001; Chitwan Tharu: Leal 1972, Danish: Haberland 1994; Garo: Burling 1992, Nootka: Shank \& Wilson 2000; Tümpisa (Panamint) Shoshone: Dayley 1989).

For instance, Umeda (1978) analyzed the occurrence of glottal stops in American English in dependence on several factors such as speaker's reading style, difficulty of the material, the segmental context, stress conditions, type of words (functional vs. lexical), and frequency of occurrence of words. Umeda's results show that speaker's reading style and difficulty of material influence the insertions of glottal stops more strongly than phonological and grammatical factors. Furthermore, slow speech rate and grammatical breaks (e.g. after adverbs as 'however' or 'instead') also induce a higher percentage of glottal stops than high speech rate and fluent speech without breaks. Finally, the study shows that rare words are more frequently marked with glottal stops than common words.

Redi \& Shattuck-Hufnagel (2001), who investigated glottalization at phrase boundaries which are medial or final in an utterance in American English, also stress the great range in the rate of glottalization in individual speakers' pronunciations. The study reports that this rate is higher for words at the ends of utterances than for words at the ends of utterance-medial intonational phrases, and it is higher at the boundaries of full intonational phrases than at those of intermediate intonational phrases.

Kohler's (1994) study, which focuses on glottal stops and glottalization in word-initial and word-medial position in German read speech of a North German variety, also highlights the variation issue. Kohler reports on the occurrence of glottal stops and glottalization as boundary markers on the one hand and as reduction phenomena of supraglottal stop articulations on the other hand. The results indicate that after pauses/silence, the presence of a glottal stop is more frequent than its absence. Stressed vowels also substantially favour the presence of glottal stops/glottalization than unstressed ones after a segmental 
context. At word-intial boundaries the highest proportion of glottal stops is found before stressed vowels and after stops (72\%), (other segments include vowels, sonorants, and fricatives). The glottal closure may also completely replace the supraglottal constriction, e.g. Freita[k a]bend is pronounced as Freita[? a]bend (Kohler 1994:45).

Studies on prosodic insertions cited below show that glottal stops/glottalizations are found at boundaries of several prosodic units such as: syllable, foot, phonological word, clitic group, phonological phrase, intonational phrase and phonological utterance (cf. prosodic hierarchy proposed by Nespor \&Vogel 1988 [2007:16]).

In the Bisu language, in onsetless syllables, the vowel which constitutes the nucleus usually carries a preceding glottal stop.

(26) Bisu

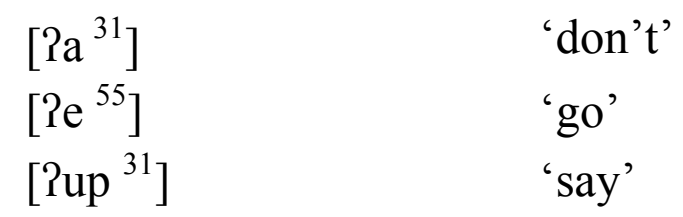

(Shixuan 2001:22)

In German, glottal stops/glottalizations occur optionally at the beginning of a vowel-initial foot, i.e. as onsets of stressed syllables, cf. examples in (27) (Hall 1992, also Wiese 2000).

(27) German

arm

oft

[?aRm] or [aRm]

'poor'

Theater

[?९ft] or [oft]

'often'

(Hall 1992:58)

[te.Pá:.te] or [te.á:.te] 'theater'

In Selayarese (an Austronesian language), a glottal stop is inserted initially in the 'intonation unit' cf. examples in (28) (Mithun \& Basri 1986, cited in Lombardi 2002:266).

(28) Selayarese

Pinnĩ

Paapa innĩ

(Mithun \& Basri 1986) 
In Anejom, a Vanuatu language, all vowels are preceded by a non-phonemic glottal stop in utterance-initial position, cf. examples in (29) ('denotes an accent).

\begin{tabular}{|c|c|c|}
\hline Anejom & & \\
\hline /et apam aen/ & 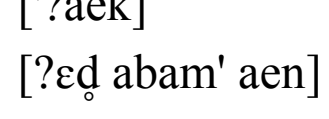 & \\
\hline
\end{tabular}

Other frequent insertions found at edges of prosodic constituents are glottal fricatives. It seems that these are found especially in final position rather than in initial positions. Blust (2009) found the insertion of $[\mathrm{h}]$ at the prosodic-word final position in several Austronesian languages like e.g. Aklanon (and other Bisayan dialects of the C. Philippines), Tagabili, Taosung, many northern and central Sarawak languages, including: Miri, Narum, Kiput, Berawan, Western Penan, Long Wat Kenya, Sebop, Kelabit, Dalat, Matu, Serike Malanau. Blust also provides several examples of glottal stop insertion at the prosodic-word final position.

Note that the insertion of a glottal fricative is in opposition to a requirement for syllables not to have codas (expressed by the constraint NoCODA in Optimality Theory).

The presence of $[\mathrm{h}]$ in final positions, especially in larger prosodic units such as phonological phrases or utterances might be attributed to aerodynamics. In particular, towards the end of a given constituent (phrase, utterance) speakers begin spreading the vocal folds in anticipation of non-speech breathing (Lisker et al. 1969). This effect is accompanied by the decline in subglottal pressure over the course of an utterance (e.g. Westbury \& Keating 1986). The outcoming air flow might be eventually perceived as a glottal fricative by listeners. This hypothesis requires, however, a detailed aerodynamic study.

Besides glottal segments, coronal segments are inserted at prosodic boundaries. The following examples illustrate the insertion of $[\mathrm{r}]$ and $[\mathrm{n}]$.
Anejom
inpeke Anejom > inpeke [r] Anejom island Aneityum
'the island of Aneityum'

(Lynch 2000: 29)

In Anejoñ, trilled [r] is inserted between words in the same phrase when a vowel-final word is followed by a vowel-initial one, cf. (30). As stressed by Lynch (2000) the latter process appears to be a variable or infrequent rule. (The trilled $[\mathrm{r}]$ is also inserted in compounds when a morpheme ending in a back 
vowel is followed by a vowel-initial morpheme, e.g. awo-upni $>$ awo[r]upni 'do well'.)

In Tunica, phrasal-final words end in a consonant. There are two strategies to meet this requirement: deletion of a word-final vowel, which applies in a limited number of words, and epenthesis of a phrase-final consonant, a strategy followed in most cases. The consonant which is epenthesized is the nasal [n]. Examples are provided in (31).

(31) Tunica

$\begin{array}{lll}\text { hatika } & \text { hatika[n] } & \text { 'again' } \\ \text { sahku } & \text { sahku[n] } & \text { 'one' }\end{array}$

Haas (1940) cited after Lombardi (2002:233)

In summary, glottal stops and fricatives are preferable sounds crosslinguistically as far as prosodic insertions are concerned. Prosodic insertions take reference to prosodic boundaries/domains. It remains to be seen to what extent they are explicable phonetically. This type of insertion is variable, especially when higher prosodic units are concerned, depending on factors such as speech rate, phrasal position, degree of prosodic prominence, word type, segmental context and others.

\section{Previous approaches}

Although it seems that consonantal insertions in comparison to vocalic insertions have been investigated considerably less frequently, there are several approaches dealing with consonantal epentheses. These, however, are mostly limited to selected languages, cf. e.g. Ortmann (1998), Alber (2001), Kawahara (2002), Ito \& Mester (2009).

There are also a few studies such as Rubach (2000), Lombardi (2002), Uffmann (2007), de Lacy (2006) and Blevins (2007) which analyze consonantal epentheses from a broader, cross-linguistic perspective and offer a unified account of them. Whereas the first four studies approach the epentheses from the markedness point of view, the latter one takes a different route: it analyzes naturalness and unnaturalness of the processes by focussing on phonetic properties of the inserted sounds and their contexts as well as the historical background. In the following sections, selected approaches will be briefly sketched and commented. 


\subsection{Lombardi (2002)}

Lombardi's approach (2002) treats insertions from the point of view of markedness. She argues, running counter to Prince \& Smolensky (1993) assumptions, that the Place markedness hierarchy should be revised to include Pharyngeal as the least marked place, cf. hierarchies provided in (32a) and (b).

Pharyngeals - in Lombardi's account comprising only [? h] - occur indeed as epenthetic consonants, but as Lombardi shows, only in specific situations. The best candidates for epenthesis are glottal consonants, which are frequently epenthetic. This is because they are the least marked in the Place markedness hierarchy and more specifically, they lack a place node.

(32) Place markedness hierarchy

a. $\quad *$ Dors, $*$ Lab $>>*$ Cor (Prince \& Smolensky 1993)

b. $\quad *$ Dors, ${ }^{*}$ Lab $>>*$ Cor $>>*$ Phar (Lombardi 2002)

Lombardi (2002) offers an explanation of insertions by proposing the place markedness scale in $(32 \mathrm{~b})$ where *Pharyngeals ([? h]) are the least marked segments and therefore the most optimal candidates for epenthesis.

Several examples provided by Lombardi are aimed at showing that $[? \mathrm{~h}]$, being the best candidate for insertions, are sometimes blocked by other restrictions (constraints). In such a case, the next candidate, i.e. a coronal, is epenthesized. The analyses show that whereas a glottal stop is a phonologically driven epenthetic consonant, e.g. inserted in order to satisfy the Onset constraint, coronals only occur in specific, mostly morphologically restricted cases.

A major objection to Lombardi's proposal is that insertions are not treated with respect to context, which implies that every context potentially allows (glottal) insertions. As several examples in 2.1. show, this claim is not evidenced by cross-linguistic data as they are motivated not only by the context, but also by morphological restrictions. Following the line of Lombardi's reasoning it is difficult to explain why e.g. certain languages epenthesize $[\mathrm{s}]$ instead of $[\mathrm{t}]$. It seems that the hierarchy in (32b) is indifferent as far as the choice of a particular consonant within a given class is concerned, which leaves a broad spectrum of choices even within a natural class. However, as far as e.g. coronals are concerned, the choice is not random, but as the examples show, [t]-epenthesis takes place relatively often while others (see [s]) seem not to occur at all. This conclusion leads us to a crucial point, namely, that the analysis by Lombardi does not differentiate between different types of insertions. German [?]insertion, an example provided by Lombardi, is clearly an optional, prosodically motivated process, cf. (27). In Lombardi's analysis it serves to support the unmarkedness of glottal stops and therefore the scale in (32b), whereas the same 
scale is meant to account for morphologically conditioned processes. In other words, it seems that different levels of representation (including phonological, morphological and prosodic/phonetic) are treated as one homogenous representation.

\subsection{Uffmann (2007)}

Although the study by Uffmann (2007) focuses on [I]-epenthesis in English, it also offers a unified account of consonantal insertions. Similarly to Lombardi's (2002) approach, Uffmann's proposal is based on markedness scale(s), but in contrast to Lombardi, the account takes into consideration both segments and the position in which they are frequently found. His approach refers to scales which align prominent positions with prominent segments, cf. (33), according to which a vowel is highly preferable in a peak syllable position (least marked) and least preferable in a syllable margin (highly marked). A laryngeal segment is least marked in a syllable margin position and highest marked in a syllable peak position, cf. (33a,b).

(33) Markedness scales: segments in margin and peak position

(a) $*$ Margin $/ \mathrm{V}>>*$ Margin $/ \mathrm{r}>>*$ Margin $/ 1>>*$ Margin $/$ nas $>>*$ Margin/obs $>$ *Margin/lar

(b) *Peak/lar $>>$ Peak/obs $>$ P Peak/nasal $>$ P Peak/l $>>*$ Peak/r $>>*$ Peak/V Prince \& Smolensky (1993)

Uffmann makes use of the scale in (33a) when he proposes an account of glottal stop epenthesis which frequently appears in a margin position. In Uffmann's example, the glottal stop is inserted in the word-initial position of a one-syllabic word which is also an onset position. If a word with more syllables were evaluated, an additional constraint would have to be proposed in order to place the glottal stop at the word-initial position. Clearly, if there is a hiatus, most languages resolve it by inserting a glide, and not a glottal stop. In order to ensure an epenthesis of a glide intervocalically, Uffmann (2007) proposes another markedness scale with special reference to the intervocalic context. The scale is shown in (34).

(34) Markedness scale: segments in the intervocalic context

$* \mathrm{~V}_{-} \mathrm{V} / \mathrm{lar}>>* \mathrm{~V}_{-} \mathrm{V} / \mathrm{obs}>>* \mathrm{~V}_{-} \mathrm{V} / \mathrm{nas}>>* \mathrm{~V}_{-} \mathrm{V} / \mathrm{l}>>* \mathrm{~V}_{-} \mathrm{V} / \mathrm{r}>>* \mathrm{~V}_{-} \mathrm{V} / \mathrm{V}$ Uffmann (2007)

The scale in (34) treats a laryngeal segment as highly marked in the intervocalic position and a vowel (or a glide) as the most preferred segment, i.e. the least 
unmarked. According to this proposal, glottal stops are inserted to maximize the contrast with the following vowel, and thus the perceptual salience of the epenthetic segment, and glides are inserted to minimize the contrast to the following or preceding vowel, and thus the perceptual salience of the epenthetic element (Uffmann 2007:458). Furthermore, the contrastiveness statements are according to Uffmann (2007) - enhanced by the degree of phonetic realisation which may vary, i.e. glide insertion is optional in many languages, and the degree of gliding may vary, whereas 'glottal stop epenthesis hardly ever shows this amount of variability' (Uffmann 2007:458). However, several experimental studies on glottal stops and glottalization cited in section 2.3.1. point to the opposite conclusion, namely, glottal stops show an almost chameleon-like behaviour in terms of inter- and intra-speaker variation, cf. also PompinoMarschall \& Zygis (2010).

It also remains unclear why the inserted glide should be similar to a vowel if one considers the fact that the contrast between the onset and the peak should be maximized in an optimal CV syllable. Moreover, some languages show free variation between glides and glottal stops found in intervocalic position, and it would be difficult to account for this with markedness constraints based on the scale in (34). Selected examples are given in (35).

German

$\begin{array}{llll}\text { Hi.[?]á.tus } & \text { or } & \text { Hi.[j]á.tus } & \text { 'hiatus' } \\ \text { Lin.gu.[?]ís.tik } & \text { or } & \text { Lin.g[v]ís.tik } & \text { 'linguistics' } \\ \text { (Alber 2001) } & & & \end{array}$

Finally, in light of the diversity of cross-linguistic data partly presented in the previous sections and the scale in (34), other questions arise, as for instance why some languages prefer the epenthetic [n], as e.g. Alemannic, instead of [r], as is the case in Bavarian or Ilocano. More importantly, it is not clear why the languages do not employ the least unmarked epenthetic candidates, which would be in line with OT assumptions.

\subsection{Blevins (2007)}

A drastically different view on insertions from the ones presented above is taken by Blevins (2007) who argues against markedness as the driving force of epenthesis. Blevin's arguments refer to (i) the position of the inserted segments as governed by constraint ONSET demanding syllables to have onsets as well as (ii) the quality of the inserted segment interpreted in terms of segmental markedness constraints. By providing several examples Blevins claims that accounts of epenthesis in terms of fulfilling the constraint ONSET encounter severe problems if cross-linguistic data are taken into consideration. For 
example, if an epenthetic consonant occurs at the beginning of a prosodic domain but not intervocalically within the same domain, then the ONSET-filling approach is difficult to maintain. Arguing against the segmental markedness constraints, Blevins claims that markedness constraints are not able to account for the fact that in cases where the epenthetical sounds are not explicable in phonetic terms and the insertion processes can be reconstructed, epenthetic sounds are those for which earlier consonant loss is evidenced. There are two other arguments brought forward by Blevins: it is not possible to account for highly marked epenthetic consonants by the segmental markedness constraints, and finally, it appears that in some languages the epenthetic consonant is not a contrastive segment and is therefore unlikely to be a direct consequence of the interplay of segmental markedness constraints (but see the discussion in 3.2 on this point).

Blevins (2007) analyzes insertions against their historical background. She differentiates between natural and unnatural histories for patterns of consonant insertions by making no reference to syllable onset or segmental markedness. In the domain of natural histories, glide and laryngeal epenthesis are found, while consonants which were/are subject to coda weakening and evolved into epenthesis processes are counted as unnatural histories. Finally, a mix of natural and unnatural history in some epenthetical processes is also found.

Although Blevins's approach differs from the present one which refers to representational levels and dispenses with diachronic data as an explanation source, there are some important points which both approaches share. First, the concept of markedness is definitely rejected as an explaining tool for consonantal epentheses as it does not differentiate between different types of processes. Second, both approaches take into consideration phonetic facts which in consequence lead to a clear differentiation between various epenthesis types.

\section{Summary}

The present study offers a systematization of consonantal insertions by classifying them into three main types; (i) grammatical, (ii) phonetic, and (iii) prosodic insertions. In addition, it has been shown that in some cases the epenthesized segment depends not only on morphology/syntax but is also conditioned prosodically and/or phonetically.

The epenthesis types significantly differ from each other with respect to some parameters, as e.g. preferred sounds, domains of application, the role of segmental context, their appearance (or absence) cross-linguistically, or the extent of variation and phonetic explication.

While grammatical insertions take reference to morphological or syntactic constituents/rules, prosodic insertions are bound to prosodic boundaries/constituents. By contrast, phonetic insertions depend on their neighbouring sounds. The insertions significantly differ with respect to preferred 
sounds. Whereas grammatical insertions seem to prefer coronal sounds, prosodic insertions are mostly restricted to glottal stops and fricatives, and phonetic insertions to glides and stops (coronal, labial, and velar). As far as the role of the segmental context is concerned, it conditions phonetic insertions, but less so prosodic ones, and seems to have no influence on grammatical insertions. This property is related to the fact that grammatical insertions are idiosyncratic, characteristic for one particular language, whereas both phonetic and prosodic insertions of the same type are found cross-linguistically. In the same vein, grammatical insertions are (mostly) not explicable phonetically, while phonetic insertions are output of the interaction of phonetic principles. It remains to be seen to what extent prosodic insertions can be explained by phonetic notions, especially in terms of glottal and supraglottal coordination. Finally, a clear difference between grammatical epentheses on the one hand and phonetic and prosodic epentheses on the other hand regards their phonetic realization in terms of inter- or intra-speaker variation: whereas the former are not subject to variation, the latter vary to a great extent.

Table 3 provides an overview of the most important characteristics of different types of consonantal insertions.

Table 3: An overview of consonantal insertions.

\begin{tabular}{|c|c|c|c|c|c|c|}
\hline $\begin{array}{l}\text { Type of } \\
\text { insertion }\end{array}$ & $\begin{array}{l}\text { Preferred } \\
\text { sounds }\end{array}$ & Domains & $\begin{array}{l}\text { The role of } \\
\text { segmental } \\
\text { context }\end{array}$ & Appearance & $\begin{array}{l}\text { Phonetically } \\
\text { explicable }\end{array}$ & Variation \\
\hline $\begin{array}{l}\text { Gramma- } \\
\text { tical }\end{array}$ & $\begin{array}{l}\text { coronals } \\
\text { (stops, glides, } \\
\text { rhotics) }\end{array}$ & $\begin{array}{l}\text { morphological/ } \\
\text { syntactic }\end{array}$ & $\begin{array}{l}\text { context- } \\
\text { independent }\end{array}$ & idiosyncratic & no & no \\
\hline Phonetic & $\begin{array}{l}\text { glides: j, w, } \\
\text { stops: coronal, } \\
\text { labial \& velar }\end{array}$ & $\begin{array}{l}\text { no reference to } \\
\text { domains }\end{array}$ & $\begin{array}{l}\text { context- } \\
\text { dependent }\end{array}$ & $\begin{array}{l}\text { cross- } \\
\text { linguistically }\end{array}$ & yes & yes \\
\hline Prosodic & $\begin{array}{l}\text { glottal stops } \\
\text { and fricatives }\end{array}$ & $\begin{array}{l}\text { prosodic } \\
\text { domains }\end{array}$ & $\begin{array}{l}\text { context- } \\
\text { independent } \\
\text { (to some } \\
\text { extent) }\end{array}$ & $\begin{array}{l}\text { cross- } \\
\text { linguistically }\end{array}$ & partly (?) & great \\
\hline
\end{tabular}

The present study considerably differs from other analyses of consonantal epentheses (a selection of which is presented in section 3) in the sense that it neither invokes markedness, as this appears problematic in light of crosslinguistic data, nor the diachronic state of processes. Instead, it considers the different nature of the epenthetic segments by referring to the representational levels or domains which are relevant for their appearance. The fact that epentheses are different in their nature can be additionally underpinned by 
phonetic evidence partly available in the literature, i.e. phonetic insertions show different phonetic characteristics from their underlying counterparts, e.g. 'intrusive' [ $t$ ] is shorter than the underlying [t] (Fourakis \& Port 1986). The hypothesis that phonetic insertions also differ from grammatical ones in terms of phonetic parameters I leave open for further studies.

\section{Acknowledgments}

I would like to thank T.A. Hall, Stefanie Jannedy, Jaye Padgett, Melanie Weirich and audiences at the Workshop on Form and Function of Insertions and Deletions in Speech (Osnabrück' 09) for valuable comments on this paper. The usual disclaimers apply. This research has been supported by Federal Ministry of Education and Research (01UG0711).

\section{References}

Alber, Birgit (2001). Regional variation and edges: Glottal stop epenthesis and dissimilation in standard and southern varieties of German. Zeitschrift für Sprachwissenschaft 20, 341.

Andersson, Erik (1994). Swedish. In: König, Ekkehard \& Johan van der Auwera (eds.). The Germanic Languages. London: Routledge, 271-312.

Blevins, Juliette. (2007). Consonant epenthesis: natural and unnatural histories. In: Good, Jeff (ed.) Language universals and language change. Oxford: OUP, 79-107.

Bayer, Josef \& Ellen Brander (2008). On Wh-Head-Movement and the Doubly-Filles-Comp Filter. Proceedings of the $26^{\text {th }}$ West Coast Conference on Formal Linguistics 87-95.

Bayer, Josef \& Ellen Brander (submitted). Wie oberflächlich ist die syntaktische Variation zwischen Dialekten? Doubly-filled COMP revisited. Ms. Universität Konstanz.

Booij, Geert (1983). Principles and parameters in phonology. Linguistics 21, 249-280.

Burling, Robbing (1992). Garo is a minimal tone language. Linguistics of the Tibeto-Burman Area, 15.5: 33-51.

Blust, Robert (2009). The Austronesian Languages. Canberra: Pacific Linguistics, Research School of Pacific and Asian Studies, Australian National University

Clements, G. Nick (1987). Phonological feature representation and the description of intrusive stops. Parassesion on Autosegmental and Metrical Phonology. Chicago: Chicago Linguistic Society, 29-50.

Dayley, Jon P. (1989). Tümpisa (Panamint) Shoshone Grammar. University of California. Publications in Linguistics. 115.

Dinnsen, Daniel A. (1980). Phonological rules and phonetic explanation. Journal of Linguistics 16, 171-191.

Donegan, Patricia \& David Stampe (1979). The study of natural phonology. In: Dennisen, Daniel (ed.). Current Approaches to Phonological Theory. Bloomington: Indiana University Press, 126-173. 
Foulkes, Paul \& Gerard J. Docherty (2000). Another chapter in the story of /r/: labiodental variants in British English. Journal of Sociolinguistic 4, 30-59.

Fourakis, Marios \& Robert Port (1986). Stop epenthesis in English. Journal of Phonetics 14, 197-221.

Gick, Bryan (1999). A gesture-based account of intrusive consonants in English. Phonology $16,29-54$.

Gick, Bryan (2002). An X-ray investigation of pharyngeal constriction in American English schwa. Phonetica 59, 38-48.

Gick, Bryan, Kang, Min A. \& Douglas H. Whalen (2002). MRI evidence for commonality in the post-oral articulations of English vowels and liquids. Journal of Phonetics 30, 357371.

Gutch, Donald (1992). Linking and intrusive $r$ in English and Bavarian. In: Blank, Claudia (ed.) Language and Civilization: A Concerted Profusion of Esseys and Studies in Honor of Otto Hietsch. Frankfurt/Main: Lang, 555-611.

Haberland, Hartmut (1994) Danish. In: König, Ekkehard \& Johan van der Auwera (eds.). The Germanic Languages. London: Routledge, 313-348.

Hall, Tracy A. (1992). Syllable Structure and Syllable-Related Processes in German. Tübingen: Max Niemeyer Verlag.

Haas, Mary R. (1940). Tunica. In: Handbook of American Indian languages. Vol.4. New York: J.J. Augustin, 1-143.

Ito, Junko \& Armin Mester (2009). The extended prosodic word. In: Grijzenhout, Janet \& Bariş Kabak (eds.) Phonological Domains. Universals and Deviations. Berlin: Mouton de Gruyter. 135-194.

Ito, Junko \& Armin Mester (to appear). The onset of the prosodic word. In: Parker, Steve (ed.) Phonological Argumentation: Essays on Evidence and Motivation. London: Equinox.

Kabak, Baris \& René Schiering (2006). The phonology and morphology of function word contractions in German. Journal of Comparative Germanic Linguistics 9, 53-99.

Kahn, Daniel (1976). Syllable-Based Generalizations in English Phonology. Ph.D. diss., MIT. Published [1980]. Garland Press: New York.

Kawahara, Shigeto (2002). Feature recycling: Hiatus resolution by way of glide formation in Japanese. Talk presented at International Christian University, Tokyo.

Kohler, Klaus J. (1994). Glottal stops and glottalization in German. Data and theory of connected speech processes. Phonetica 51, 38-51.

Lacy, de Paul (2006). Markedness: Reduction and Preservation in Phonology. Cambridge: Cambridge University Press.

Leal, Dorothy (1972). Chitwan Tharu Phonemic Summary. Kirtipur: Summer Institute of Linguistics and Institute of Nepal Studies, Tribhuvan University. 
Lisker, Leigh, Abramson, Arthur S., Cooper, Franklin S. and Malcolm H. Schvey (1969). Transillumination of the larynx in running speech. Journal of the Acoustical Society of America 45, 1544-1546.

Lombardi, Linda (2002). Coronal epenthesis and unmarkedness. Phonology 19, 2, 219-251.

Lynch, John (2000). A Grammar of Anejom. Pacific Linguistics 507. Canberra: The Australian National University.

McCarthy, John (1993). A case of surface constraint violation. Canadian Journal of Linguistics 3, 127-153.

McCarthy, John (1991). Synchronic rule inversion. In: Sutton, Laurel, Christopher Johnson, $\&$ Ruth Shields (eds.). Proceedings of the Seventeenth Annual Meeting of the Berkeley Linguistics Society. 192-297.

McCarthy, John (1993). A case of surface constraint variation. Canadian Journal of Linguistics 38, 127-153.

McMahon, April M.S. (2000). Change, Chance, and Optimality. Oxford: Oxford University Press.

McMahon, April, Foulkes, Paul \& Laura Tollfree (1994). Gestural representation and lexical phonology. Phonology 11, 277-316.

Millardet, Georges (1923). Linguistique et Dialectologie Romanes. Problèmes et Methods. Paris: Champion.

Mithun, Marianne \& Hasan Basri (1986). The phonology of Selayarese. Oceanic Linguistics $25(1 / 2), 210-254$.

Mudzingwa, Calisto (2007). Hiatus resolution in Shona. University of British Columbia. Ms.

Nespor, Marina \& Irene Vogel (1988 [2007]). Prosodic Phonology. Berlin: Mouton de Gruyter.

Ohala, John J. (1974). Experimental historical phonology. In: Anderson, John M. \& Charles Jones (eds.) Historical Linguistics II: Theory and Description in Phonology. Amsterdam: North-Holland Publishing, 353-389.

Ohala, John J. (1981). The listener as a source of sound change. In: Masek, Carrie S., Roberta A. Hendrick, \& Mary F. Miller (eds.). Papers from the Parasession on Language and Behavior. Chicago: CLS, 178-203.

Ohala, John J. (1995). A probable case of clicks influencing the sound patterns of some European languages. Phonetica 52, 160-170.

Ortmann, Albert (1998). Consonant epenthesis: its distribution and phonological specification. In: Kehrein, Wolfgang and Richard Wiese (eds.). The Phonology and Morphology of Germanic Languages. Niemeyer: Tübingen, 51-76.

Payne, David L. (1981). The phonology and morphology of Axinica Campa. Arlington: Summer Institute of Linguistics \& University of Texas at Arlington. 
Pierrehumbert, Janet (1994). Prosodic effects on glottal allophones. In: Fujimura, Osamu and Minoru Hirano (eds). Vocal Fold Physiology 8: Voice Quality Control. Singular Press, San Diego, 39-60.

Pierrehumbert, Janet \& David Talkin (1991). Lenition of $/ \mathrm{h} /$ and glottal stop. In: Kingston, John \& Mary E. Beckman (eds.) Papers in Laboratory Phonology II. Cambridge: University Press, 90-117.

Pigott, Glyne L. (1980). Aspects of Odawa Morphophonemics. New York: Garland.

Pigott, Glyne L. \& Rajendra Singh (1985). The phonology of epenthetic segments. The Canadian Journal of Linguistics 30, 247-405.

Pompino-Marschall, Bernd \& Marzena Zygis (2010). Glottal marking of vowel-initial words in German. ZAS Papers in Linguistics (this volume).

Prince, Alan \& Paul Smolensky (1993). Optimality Theory: Constraint Interaction in Generative Grammar. Ms. Rutgers University \& University of Colorado, Boulder.

Redi, Laura \& Stefanie Shattuck-Hufnagel (2001). Variation in the realization of glottalization in normal speakers. Journal of Phonetics 29, 407-429.

Rialland, Anne \& Redouane Djamouri (1984). Harmonie Vocalique, Consonantique et Structures de Dependance dans le Mot en Mongol Khalkha. Bulletin de la Societe de Linguistique de Paris 79.

Rubach, Jerzy (1984). Cyclic and Lexical Phonology. The Structure of Polish. Dordrecht: Foris.

Rubach, Jerzy (2000).Glide and glottal stop insertion in Slavic languages: a DOT analysis. Linguistic Inquiry 31, 271-317.

Schutter de, Georges (1994). Dutch. In: König, Ekkehard \& Johan van der Auwera (eds.). The Germanic Languages. London: Routledge. 439-477.

Selkirk, Elisabeth O. (1980a). The role of prosodic categories in English word stress. Linguistic Inquiry 11, 563-605.

Selkirk, Elisabeth O. (1980b). Prosodic domains in phonology: Sanskrit revised. In: Arnoff, Mark \& Kean Mary-Louise (eds.). Juncture. A collection of Original Papers. Saratoga: Anma Libri. 107-129.

Shank, Scott \& Ian Wilson (2000). An acoustic analysis of vowel formants in pharyngeal and glottal contexts in Nuu-chah-nulth. University of Washington Working Papers in Linguistics 19, 75-84.

Shixuan, Xu (2001). The Bisu Language. München: Lincom.

Smith, Jennifer L. (2001). Lexical category and phonological contrast. In: Kirchner, Robert, Pater, Joe \& Wolf Wikely (eds.) Proceedings of the Workshop on the Lexicon in Phonetics and Phonology. Edmonton: University of Alberta, 61-72.

Thráinsson, Höskuldur (1994). Icelandic. In: König, Ekkehard \& Johan van der Auwera (eds.). The Germanic Languages. London: Routledge. 142-189. 
Uffmann, Christian (2007). Intrusive [r] and optimal epenthetic consonants. In: Carr, Philip \& Patrick Honeybone. Special volume of Languages Science 29, 451-476.

Umeda, Noriko (1978). Occurrence of glottal stops in fluent speech. JASA 64, 81-94.

Vennemann, T (1988). Preference Laws for Syllable Structure and the Explanation of Sound Change. Berlin: Mouton de Gruyter.

Vincent, Nigel (1988). Italian. In: Harris, Martin \& Vincent, Nigel (eds.). The Romance Languages. London: Routledge, 279-313.

Wells, John, C. (1982). Accents of English. Cambridge, U.K.: Cambridge University Press.

Westbury, John R. \& Patricia A. Keating (1986). On the naturalness of stop consonant voicing. Journal of Linguistics 22, 145-166.

Wetzels, Leo W. (1985). The historical phonology of intrusive stops. A nonlinear description. Canadian Journal of Linguistics 30, 285-333.

Wiese, Richard (2000). The Phonology of German. Oxford: Oxford University Press.

Zwicky, Arnold M. (1972). Note on a phonological hierarchy in English. In: Stockwell, Robert P. \& Roland K. S. Macaulay (eds.). Linguistics Change and Generative Theory. Bloomington: Indiana University Press, 275-301.

Zec, Draga. (2005). Prosodic Differences among Function Words. Phonology 22, 77-112.

Zygis, Marzena (2009). A perceptual study on glide insertions. ZAS, Berlin. Ms. 